\title{
Review: probiotics reduced diarrhoea at 3 days in children and adults with proven or presumed infectious diarrhoea
}

Allen SJ, Okoko B, Martinez E, et al. Probiotics for treating infectious diarrhoea. Cochrane Database Syst Rev 2004;(2):CD003048.

Are probiotics effective for proven or presumed infectious diarrhoea in children and adults?

\section{METHODS}

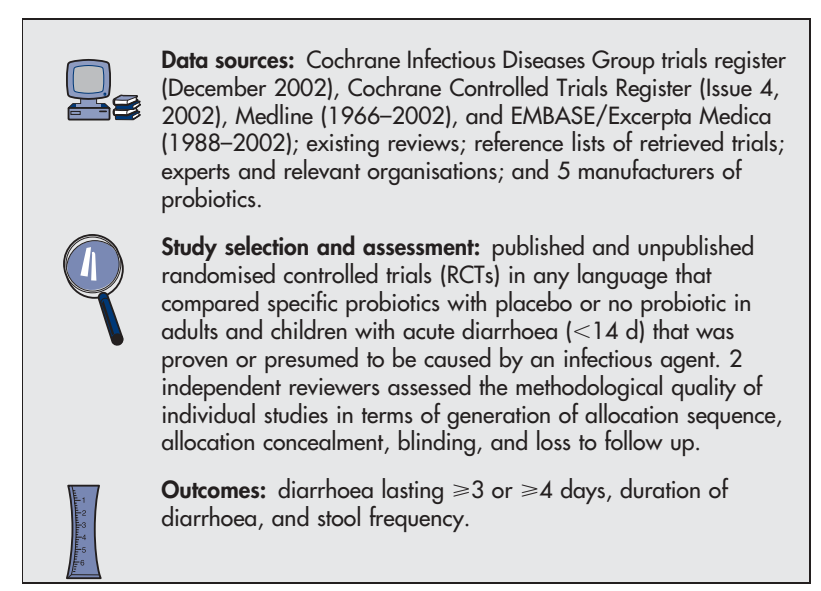

\section{MAIN RESULTS}

23 studies ( $\mathrm{n}=1917,76 \%$ children) met the selection criteria Probiotics included lactic acid bacilli (2l studies) and the yeast Saccharomyces boulardii (2 studies). Comparison groups included matching placebo (20 studies), standard treatment without placebo (2 studies), and milk formula (1 study).

Meta-analysis showed that patients who received probiotics were less likely to have diarrhoea lasting $\geqslant 3$ days or $\geqslant 4$ days than patients who received placebo or no probiotics (table). Mean duration of diarrhoea was reduced in patients who received probiotics, as was stool frequency at day 2 and day 3 of the intervention (table).

\section{CONCLUSION}

In children and adults with proven or presumed infectious diarrhoea, probiotics reduced diarrhoea lasting $\geqslant 3$ days or $\geqslant 4$ days and reduced the mean duration of diarrhoea by 30 hours.

For correspondence: Dr S J Allen, Swansea Clinical School, University of Wales Swansea, Swansea, UK. s.j.allen@swansea.ac.uk

Source of funding: Department for International Development UK.

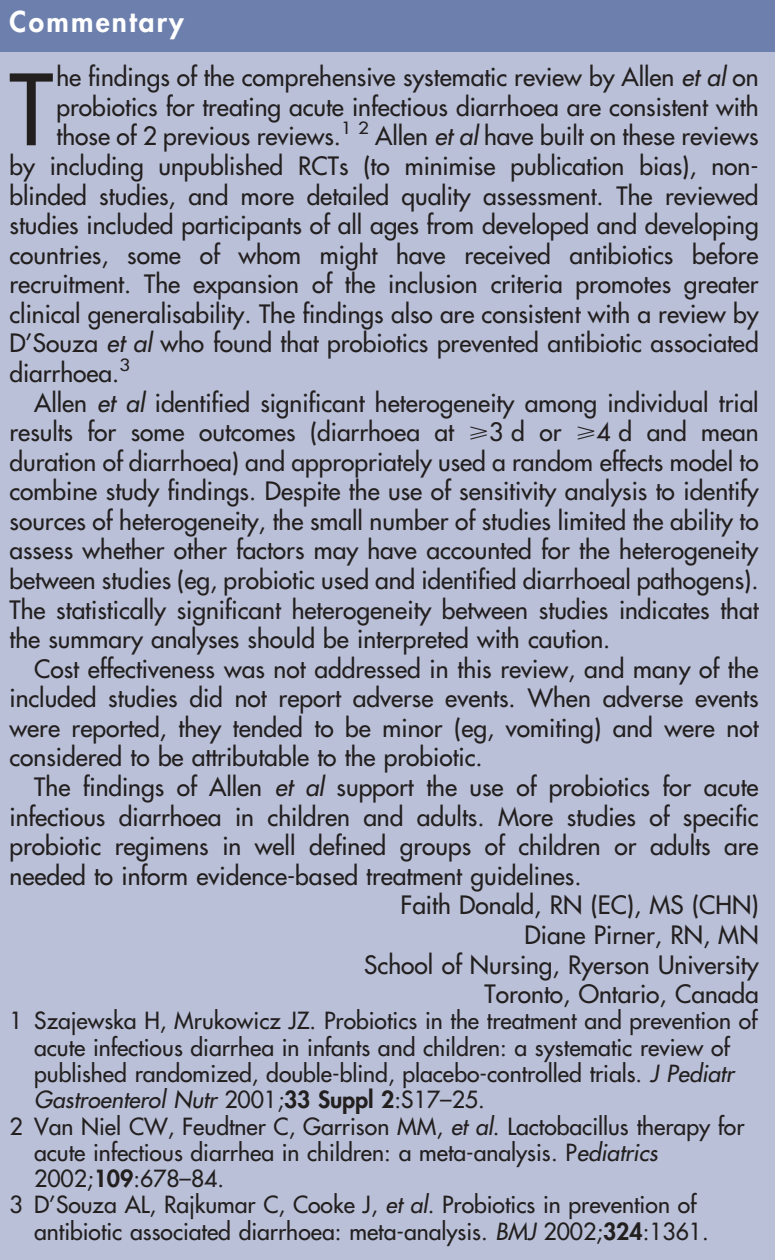

Probiotics $v$ control (placebo or no probiotics) in children and adults with proven or presumed infectious diarrhoea*

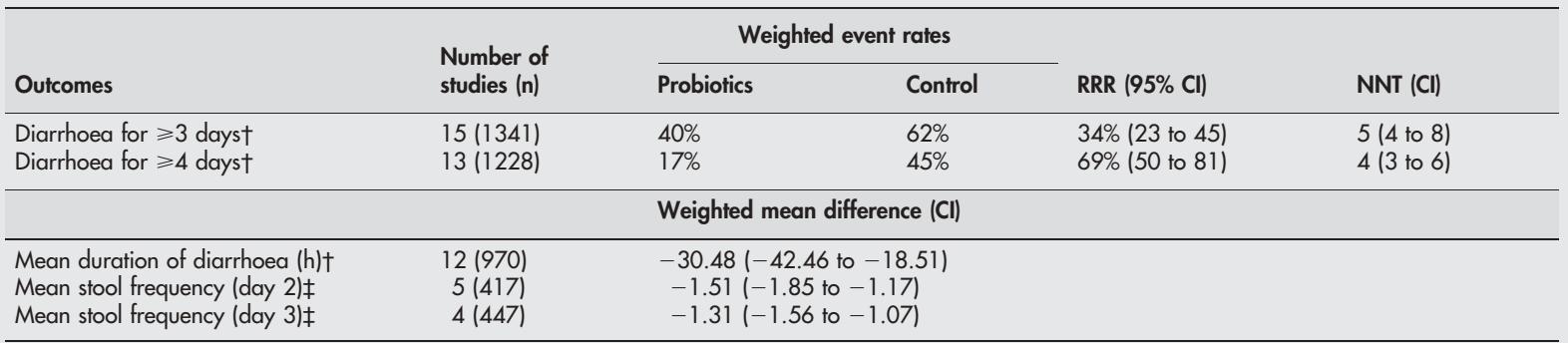

*Abbreviations defined in glossary; RRR, NNT, and Cl calculated from data in article.

†Based on a random effects model (significant heterogeneity among trials).

$\ddagger$ Based on a fixed effects model. 